\title{
BMJ Open New screening tool for neonatal nutritional risk in China: a validation study
}

\author{
Mei Zhou, ${ }^{1}$ Yuwei Li, ${ }^{2}$ Huaying Yin (D) , ${ }^{2}$ Xianhong Zhang, ${ }^{1}$ Yan $\mathrm{Hu}^{2}$
}

To cite: Zhou M, Li Y, Yin H, et al. New screening tool for neonatal nutritional risk in China: a validation study. BMJ Open 2021;11:e042467. doi:10.1136/ bmjopen-2020-042467

- Prepublication history and additional material for this paper are available online. To view these files, please visit the journal online (http://dx.doi. org/10.1136/bmjopen-2020042467).

Received 09 July 2020 Revised 13 March 2021 Accepted 22 March 2021
Check for updates

(C) Author(s) (or their employer(s)) 2021. Re-use permitted under CC BY-NC. No commercial re-use. See rights and permissions. Published by BMJ.

For numbered affiliations see end of article.

Correspondence to

Huaying Yin;

sarah6524@126.com

\section{ABSTRACT}

Objective A neonatal nutritional risk screening tool (NNRST) was developed by using Delphi and analytic hierarchy processes in China. We verified the accuracy of this tool and analysed whether it effectively screened neonates with nutritional risk.

Design Prospective validation study.

Setting and participants In total, 338 neonates who were admitted to the neonatal unit of Children's Hospital of Chongqing Medical University from May-July 2016 completed the study. Nutritional risk screening and length and head circumference measurements were performed weekly. Weight was measured every morning, and other relevant clinical data were recorded during hospitalisation. Main outcome measures We evaluated the sensitivity, specificity, validity, reliability, and positive and negative predictive value of the screening tool. Various characteristics of neonates in different risk groups were analysed to determine the rationality of the nutritional risk classification.

Results The sensitivity, specificity, and positive and negative predictive values were $85.11 \%, 91.07 \%, 60.61 \%$ and $97.43 \%$, respectively. The criterion validity was texted by the Spearman correlation analysis $(r=0.530)$ and independent samples non-parametric tests $(p=0.000)$. The content validity (Spearman correlation coefficient) was $0.321-0.735$. The inter-rater reliability (kappa value) was 0.890 . Among the neonatal clinical indicators, gestational age, birth weight, length, admission head circumference, admission albumin, admission total proteins, discharge weight, discharge length and head circumference decreased with increasing nutrition risk level; the length of stay and the rate of parenteral nutrition support increased with increasing nutrition risk level. In the comparison of complications during hospitalisation, the incidence of necrotising enterocolitis and congenital gastrointestinal malformation increased with increasing nutrition risk level. Conclusion The validation results for the NNRST are reliable. The tool can be used to preliminarily determine the degree of neonatal nutritional risk, but its predictive value needs to be determined in future large-sample studies.

Trial registration number ChiCTR2000033743.

\section{INTRODUCTION}

Nutrition during the early stages of life can have a series of consequences that extend into adulthood. Hospitalised neonates,

\section{Strengths and limitations of this study}

- This is the first validation study of a neonatal nutritional risk screening tool developed by the Delphi process and analytic hierarchy process in China.

- We verified the predictability and stability of the neonatal nutrition risk screening tool by using statistical methods to weight the results and by using multiple clinical indicators, which may have provided more accurate results.

- The similarity of the study design and statistical methods to those used in previous studies makes our findings more comparable with historical data. Although a multicentre and large-sample study that verifies the predictability and stability of the model is needed, our findings support the screening of neonatal nutritional risk in mainland China.

- As this study did not include post-term infants, we were unable to determine whether malnutrition occurred in this population.

- Bias may have occurred because infants born at less than 30 weeks of gestation were not enrolled in our study.

particularly premature and low birthweight infants, are prone to nutritional problems due to deficits in growth and adaptability, combined with the nutritional deficits that occur due to diseases associated with prematurity and feeding difficulties. ${ }^{12}$ The shortterm effects of nutritional problems may include increased morbidity and mortality, longer hospital stays and increased medical costs. The long-term effects of nutritional problems may lead to growth and development lags, delayed nerve growth and learning difficulties and may increase the risk of noncommunicable diseases. ${ }^{3-5}$ However, nutritional care may provide an effective strategy for improving short-term and long-term outcomes. ${ }^{6-8}$

In systematic nutritional care, nutritional risk screening is the first procedure to be performed. The European Society for Paediatric Gastroenterology, Hepatology and Nutrition recommends the implementation 
Table 1 Summary of existing neonatal nutrition screening tools

\begin{tabular}{|c|c|c|c|}
\hline Tool & $\begin{array}{l}\text { Target } \\
\text { population }\end{array}$ & Assessment criteria & Validation \\
\hline $\begin{array}{l}\text { Clinical Assessment of } \\
\text { Nutrition score }\end{array}$ & $\begin{array}{l}\text { Neonates soon } \\
\text { after birth. }\end{array}$ & $\begin{array}{l}\text { Birth weight, length, head circumference, } \\
\text { midarm circumference and ponderal index. }\end{array}$ & No published data. \\
\hline $\begin{array}{l}\text { Ohio Neonatal Nutritionists } \\
\text { Screening Criteria for } \\
\text { Identifying Hospitalized } \\
\text { Infants at Highest Nutritional } \\
\text { Risk }^{13}\end{array}$ & $\begin{array}{l}\text { Hospitalised } \\
\text { neonates. }\end{array}$ & $\begin{array}{l}1 \text { week of age: }>15 \% \text { weight loss since } \\
\text { birth or weight }<1 \mathrm{~kg} \text { at birth; } 1-2 \text { weeks of } \\
\text { age: }<60 \mathrm{kcal} / \mathrm{kg} / \mathrm{day} \text { or continued weight } \\
\text { loss; }>2 \text { weeks of age: intake }<66 \% \text { energy } \\
\text { requirement or weight gain }<10 \mathrm{~g} / \mathrm{kg} / \text { day or } \\
\text { low albumin/low phosphate/high bilirubin/high } \\
\text { ALP; }>2 \text { months of age: any of the above or no } \\
\text { dietary iron or continued parenteral nutrition. }\end{array}$ & No published data. \\
\hline $\begin{array}{l}\text { Neonatal nutrition screening } \\
\text { tool }^{14}\end{array}$ & NICU population. & $\begin{array}{l}\text { Gestational age and weight at birth; diagnosis } \\
\text { of absent or reversed end diastolic flow on } \\
\text { umbilical artery Doppler; diagnosis of severe } \\
\text { intrauterine growth restriction, defined as } \\
\text { a birth weight below the second centile } \\
\text { on the UK-WHO growth chart; need for } \\
\text { gastrointestinal surgery or presence of severe } \\
\text { gastrointestinal malformation; time to regain } \\
\text { birth weight; maximum percentage weight loss } \\
\text { from birth weight and minimum rate of weekly } \\
\text { weight gain from } 2 \text { weeks of age onwards. }\end{array}$ & $\begin{array}{l}\text { Sensitivity: } 89.6 \% \text {. } \\
\text { Specificity: } 75.1 \% \text {. } \\
\text { Positive predictive value: } \\
32.9 \% \text {. } \\
\text { Negative predictive value: } \\
98.1 \% \text {. }\end{array}$ \\
\hline
\end{tabular}

ALP, Alkaline phosphatase; NICU, neonatal intensive care unit.

of specialised paediatric nutritional support teams in hospitals to screen for nutritional risk. Therefore, nutritional risk screening is worthy of research and increased attention. Nutritional risk screening aims to predict the probability of a better or worse outcome due to nutritional factors and whether nutritional treatment is likely to influence this outcome. ${ }^{8}$ Nutritional risk screening tools should have some predictive significance for the clinical outcome of diseases. ${ }^{9}{ }^{10}$ Patients at high nutritional risk can be identified and supported in a timely manner with nutritional risk screening, which has the potential to improve prognoses, reduce lengths of hospitalisation and increase quality of life, among other positive outcomes. ${ }^{11} 12$

Although various nutritional risk screening tools are available in the paediatric arena, a widely accepted nutritional risk screening tool relevant to neonates is still lacking (table 1). As an example, the Ohio Neonatal Nutritionists Screening Criteria for Identifying Hospitalized Infants at Highest Nutritional Risk covers a wide range of topics, but no published data are available regarding its validity, sensitivity or specificity. ${ }^{13}$ In Johnson et $a l \mathrm{~s}^{14}$ research, a screening tool for nutritional risk in neonatal intensive care was created by a multidisciplinary group. However, this tool is suitable only for neonates in the neonatal intensive care unit. In China, because of the large annual number of births and a shortage of nutritional support teams for newborns, medical staff evaluate the nutritional status of newborns with a specific growth curve during hospitalisation, and there is no practical or professional tool with which to screen for nutritional risk among newborns. Therefore, it is necessary to develop a nutritional risk screening tool for neonates in China.

To meet this need, a group of Chinese experts comprising specialists with experience in neonatal clinical treatment, nutritional care and nursing was convened to conduct a two-round Delphi process and develop the dimension and indicator contents of the neonatal nutritional risk screening tool (NNRST). The developmental process of this tool has been described in detail in our previous articles. ${ }^{15}$ This study aimed to verify the screening accuracy of this tool and to analyse whether it can effectively screen hospitalised neonates with nutritional risk.

\section{METHODS \\ Subjects}

This was a prospective observational study that recruited infants who were admitted to the neonatal unit of Children's Hospital of Chongqing Medical University from May to July 2016. The inclusion criteria were age within 28 days after birth, admission to the neonatal ward for at least 24 hours and parental agreement to participate in the study. The exclusion criteria were as follows: lack of data on gestational age or birth weight, severe congenital malformation that interfered with the ability to take anthropometric measurements, age less than 14 days and weight that did not return to birth weight at discharge.

A total of 446 newborns were enrolled; 108 were excluded based on the third exclusion criterion. Finally, 338 newborns were eligible for this study, including 198 males and 140 females (figure 1). The mean (SD) birth 


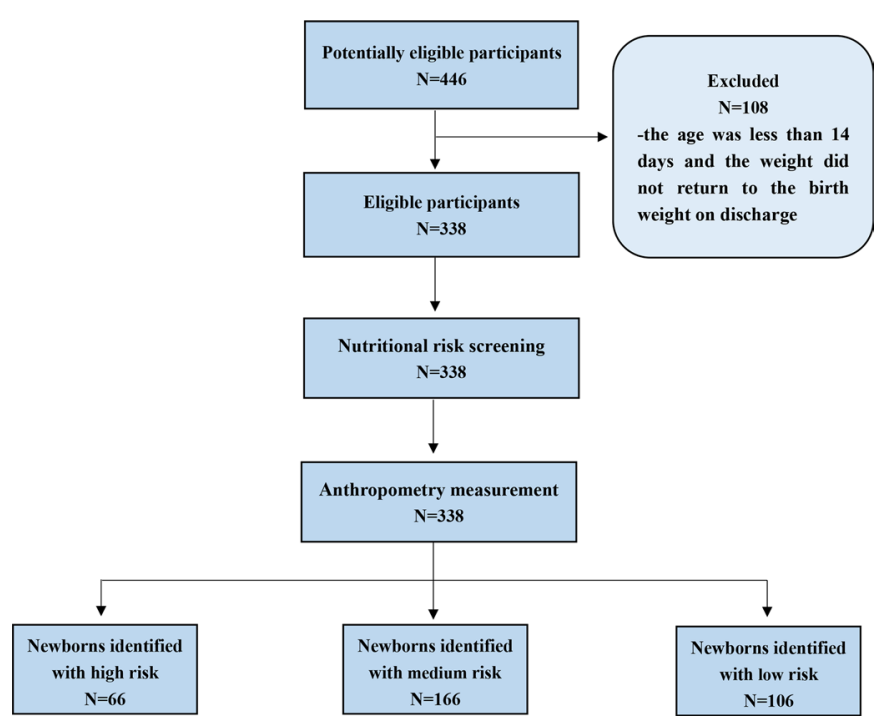

Figure 1 Flow diagram for the selection of participants.

weight was 2683.1 (710.7) $\mathrm{g}$, and the median (P25, P75) gestational age was $37.4(34.8,39.1)$ weeks. A total of 182 infants underwent caesarean section delivery. The median (P25, P75) length of stay was $9.00(6.75,13.20)$ days. The subjects were diagnosed with one or more diseases, 42 had necrotising enterocolitis/congenital gastrointestinal malformation, 32 had diarrhoea/alimentary tract haemorrhage, 21 had milk protein allergy/gastrointestinal reflux, 291 had pneumonia, 175 had septicaemia, 218 had congenital heart disease, 277 had brain injury/intracranial haemorrhage and 232 had hyperbilirubinaemia. Because there was no breast milk bank in the neonatal ward of our hospital in 2016, all the subjects were bottle-fed during hospitalisation.

\section{Data collection}

Nutritional risk screenings of the subjects were performed by two nurses at admission and then weekly until discharge. To ensure standardisation of the screening, all investigators participated in a training session before the study started.

The anthropometric measurement data for each participant were recorded by two trained nurses. The patients were weighed every morning at 08:00 during hospitalisation following a standardised method using an electronic baby scale (ACS-20-YE) that was accurate to $10 \mathrm{~g}$. Length and head circumference were measured weekly using a WB-A baby measuring bed and a standard tape measure accurate to $0.1 \mathrm{~cm}$. Each set of measurements was obtained with the measurement tools twice for each infant and then averaged.

The following information was extracted from the electronic medical records: patient identification number, sex, birth age, gestational age, birth weight, discharge date, nutrient intake and any underlying diseases.

\section{Nutritional risk screening tool}

The dimension and indicator contents of the NNRST were developed by a group comprising seven experienced neonatal clinical chief physicians, two dietitians and six neonatal nursing supervisors using a two-round Delphi process. ${ }^{15}$ The analytic hierarchy process (AHP) was used to calculate the weight coefficients for each dimension and indicator. There were 15 valid recycling questionnaires in a two-round expert consultation, and the expert enthusiasm coefficients of the two rounds were $88 \%$ and $100 \%$, respectively. The average coefficient of the degree of expert authority was 0.9 . The coordination coefficients of the indicators were 0.441 and 0.486 , indicating the consistency of the experts' opinions. The consistency ratios were all less than 0.1 , which showed satisfactory consistency of the judgement matrix. On that basis, the weight coefficients of each dimension and indicator were calculated, and the indicator scores were determined by the weight coefficients.

The NNRST comprises mainly four items and 31 indicators. The items include item I: birth situation; item II: weight change; item III: nutritional intake method; and item IV: common neonatal disease diagnosis. Because this tool performs only preliminary nutritional risk screening, it is important to regularly monitor and assess growth (length, head circumference and weight) to avoid incorrectly classifying newborns who may receive inappropriate intervention. Therefore, the NNRST needs to be combined with the 2013 revision of the Fenton growth chart for the determination of two indicators (small for gestational age and large for gestational age) and the assessment of growth.

\section{Scoring algorithm of the nutritional risk screening tool}

According to the scoring algorithm of the NNRST (see figure 2), the nutritional risk score is calculated for the sum scores of four items. The highest scores of items I, II, III and IV are 4, 4, 3 and 4, respectively, while the lowest scores are 1, 2, 1 and 1, respectively. If the newborn does not have the relevant factors on the scale, the score is 0 . Therefore, the score range of the tool is $0-15$. Nutritional risk is stratified into three levels according to the total score: $\geq 8$ for high risk, $\geq 4$ and $<8$ for medium risk and $<4$ for low risk. There are two main scoring principles.

- Never repeat scoring. The scoring process should not be repeated, and the highest score among the indicators within the same item should be used. Even if multiple indicators are scored, only the indicator with the highest score should be considered.

- When the newborn does not present an indicator on the scale, the absence of indicators in items I-III should be scored 0. Based on the doctor's diagnosis, absent indicators in item IV should be regarded as related to the corresponding disease diagnosis in the list of items being scored.

Neonates with faltering growth on admission or during their stay were considered the standard for testing the accuracy of the NNRST. Faltering growth was defined as a fall of 1.33 SD score for weight between birth and discharge, ${ }^{14}$ corresponding to a decrease across two marked centile lines on a Chinese neonatal birth weight 


\begin{tabular}{|c|c|c|c|c|}
\hline \multicolumn{2}{|l|}{ Name: } & Date of birth: & Date: & \\
\hline \multicolumn{2}{|c|}{ Bed Number: } & Gestation at birth: & Signature: & \\
\hline \multicolumn{2}{|c|}{ Gender: } & Birth weight: & Weight: & \\
\hline \multicolumn{2}{|c|}{ Items } & Indicators & Scores & Scoring \\
\hline \multirow{7}{*}{$\begin{array}{l}\text { I Birth } \\
\text { situation }\end{array}$} & \multirow{3}{*}{$\begin{array}{l}\text { Gestational } \\
\text { age }\end{array}$} & - $\quad \geq 22$ weeks and $<28$ weeks & 4 & \\
\hline & & - $\quad \geq 28$ weeks and $<32$ weeks & 3 & \\
\hline & & - $\quad \geq 32$ weeks and $<37$ weeks & 2 & \\
\hline & \multirow{4}{*}{$\begin{array}{c}\text { Birth } \\
\text { weight }\end{array}$} & . $\quad<1000 \mathrm{~g}$ & 4 & \\
\hline & & - $\quad$ SGA $(<\mathrm{P} 10)$ & 3 & \\
\hline & & - $\quad \geq 1000 \mathrm{~g}$ and $<1500 \mathrm{~g}$ & 2 & \\
\hline & & $\begin{array}{ll}\text { - } & \geq 1500 \mathrm{~g} \text { and }<2500 \mathrm{~g} \\
\text {. } & \text { LGA (>P90) } \\
\end{array}$ & 1 & \\
\hline \multirow{3}{*}{\multicolumn{2}{|c|}{ II Weight Change }} & - Weight loss $>15 \%$ & 4 & \\
\hline & & - Weight loss $>10 \%$ & 3 & \\
\hline & & $\begin{array}{l}>2 \text { weeks of age: weight gain } \\
<10 \mathrm{~g} /(\mathrm{kg} \cdot \mathrm{d}) \\
1 \sim 2 \text { weeks of age: weight decreased } \\
\text { or unaltered }\end{array}$ & 2 & \\
\hline \multirow{3}{*}{\multicolumn{2}{|c|}{ III Nutrient intake way }} & - Complete parenteral nutrition & 3 & \\
\hline & & . Partial parenteral nutrition & 2 & \\
\hline & & . Tube feed & 1 & \\
\hline \multirow[b]{5}{*}{$\begin{array}{c}\text { IV } \\
\text { Disease } \\
\text { diagnosis }\end{array}$} & \multirow{3}{*}{$\begin{array}{l}\text { Digestive } \\
\text { system } \\
\text { disease }\end{array}$} & $\begin{array}{l}\text { NEC } \\
\text { - Gastrointestinal congenital } \\
\text { malformation } \\
\end{array}$ & 4 & \\
\hline & & $\begin{array}{ll} & \text { Recurrent diarrhea } \\
\text { - } & \text { Gastric-intestinal perforation }\end{array}$ & 3 & \\
\hline & & $\begin{array}{ll} & \text { Milk protein allergy } \\
\text {. } & \text { GER }\end{array}$ & 2 & \\
\hline & \multirow[b]{2}{*}{$\begin{array}{l}\text { Other } \\
\text { disease }\end{array}$} & $\begin{array}{l}\text { Severe infection (pneumonia, } \\
\text { septicemia) }\end{array}$ & 2 & \\
\hline & & $\begin{array}{ll}- & \text { BPD } \\
\text { - } & \text { Acute illness or injury } \\
\text { - } & \text { Congenital heart disease } \\
\text { - } & \text { Glucose metabolic disorder } \\
\text { (hypoglycemia, hyperinsulinemia) } \\
\text { - } \quad \text { RDS } \\
\text { - Hypokalemia /hypocalcemia } \\
\text { - } \quad \text { Brain injury /intracranial hemorrhage } \\
\text { /periventricular leukomalacia } \\
\text { - } \quad \text { HIE } \\
\text { - }\end{array}$ & 1 & \\
\hline & & & $\begin{array}{l}\text { Aggregate } \\
\text { score }\end{array}$ & \\
\hline
\end{tabular}

Figure 2 Neonatal nutritional risk screening tool (notes: (1) this screening scale must be combined with the 2013 revision of the Fenton growth chart. (2) The scale is divided into two parts: the header and body. The content of the header is the basic information, while the body is constituted by four items and 31 indicators. There are four blank columns to the right of the overall scale, which are used to record the neonatal screening scores in aggregate and for each item and other operation information over a period of 4 weeks. The Fenton growth chart can be used for the determination of two indicators (small for gestational age infant and large for gestational age infant) and the assessment of growth (length, head circumference and weight). (3) This tool can be used on all hospitalised infants on a weekly basis. BPD, bronchopulmonary dysplasia; GER, gastrointestinal reflux; HIE, hypoxic-ischaemic encephalopathy; LGA, large for gestational age; NEC, necrotising enterocolitis; RDS, respiratory distress syndrome; SGA, small for gestational age.

curve for different gestational ages. ${ }^{16}$ The birth and discharge weights of each infant were compared and then plotted on the Chinese neonatal birth weight curve to determine whether they had faltering growth. With our tool, a result showing that the highest nutritional risk score of the infant during hospitalisation was more than 8 would be the final result used to determine an outcome that is equal to faltering growth.

\section{Statistical analysis}

According to the incidence of neonatal malnutrition $(10.9 \%)$ in China, ${ }^{17}$ the sample size was 305 cases, with an admissible error of $3.5 \%$ (the formula for sample size is $\mathrm{n}=\mathrm{Z}_{\alpha / 2}^{2} \varpi(1-\bar{\varpi}) / \delta,^{2} \bar{\omega}=0.109, \alpha=0.05, \quad \mathrm{Z}_{\alpha}=1.96$, $\delta=0.035)$. The loss rate was assumed to be $30 \%$; therefore, the sample size was expanded to $305 / 0.7=436$. The final sample size was 436 cases.

Data analysis was performed by SPSS V.21.0 (SPSS, Inc, Chicago, Illinois, USA). $\mathrm{P}<0.05$ was considered statistically significant. Measurement data with a normal distribution were compared between groups by means of the $\mathrm{F}$ test (variance analysis), and those with a skewed distribution were compared by means of the nonparametric test. Rates were compared between groups using the $\chi^{2}$ test. The correlation coefficient $(r)$ was calculated by analysing the Spearman correlation between each item score and the total score. To clarify the differences among neonates with different risk levels, pairwise comparisons among the three groups were made. The standard of the Bonferroni calibration $(\mathrm{p}=0.0167)$ was adopted in the $\chi^{2}$ and non-parametric tests.

\section{Patient and public involvement}

This research was performed without patient involvement. Patients were not invited to comment on the study design and were not consulted for the development of patientrelevant outcomes or in the interpretation of the results. Patients were not invited to contribute to the writing or editing of this document for readability or accuracy.

\section{RESULTS}

\section{Screening accuracy}

The screening accuracy was calculated using statistical cases of high-risk and faltering growth infants. Faltering growth and high-risk infants were designated as positive, while medium-risk and low-risk infants and those without faltering growth were designated as negative. As a result, the sensitivity, specificity, positive predictive value and negative predictive value of the screening tool for all infants were $85.11 \%, 91.07 \%, 60.61 \%$ and $97.43 \%$, respectively (table 2 ).

\section{Validity and reliability}

The validity of this study was shown by its criterion validity and content validity. Infants with faltering growth were the standard for criterion validity, and Spearman correlation analysis and independent samples non-parametric testing were used to test criterion validity. The scores of highrisk infants were significantly correlated with the number of infants with faltering growth $(\mathrm{r}=0.530, \mathrm{p}=0.000)$. The difference in scores between infants with faltering growth $(8(8,9))$ and those without faltering growth $(4(2,6))$ was significant $(\mathrm{Z}=-9.732, \mathrm{p}=0.000)$. The content validity was represented by the Spearman correlation analysis between each item score and the total score. The correlations between the total score and each item were positive, 
Table 2 The screening accuracy of the screening tool

\begin{tabular}{|c|c|c|c|c|}
\hline & $\begin{array}{l}\text { All infants } \\
(n=338)\end{array}$ & $\begin{array}{l}\text { High risk } \\
(n=66)\end{array}$ & $\begin{array}{l}\text { Medium } \\
\text { risk } \\
(n=166)\end{array}$ & $\begin{array}{l}\text { Low risk } \\
(n=106)\end{array}$ \\
\hline True positives & 40 & 40 & 0 & 0 \\
\hline False positives & 26 & 26 & 0 & 0 \\
\hline True negatives & 265 & 0 & 159 & 106 \\
\hline False negatives & 7 & 0 & 7 & 0 \\
\hline Sensitivity (\%) & 85.11 & 100 & 0 & - \\
\hline Specificity (\%) & 91.07 & 0 & 100 & 100 \\
\hline $\begin{array}{l}\text { Positive predictive } \\
\text { value (\%) }\end{array}$ & 60.61 & 60.61 & - & - \\
\hline $\begin{array}{l}\text { Negative } \\
\text { predictive value } \\
\text { (\%) }\end{array}$ & 97.43 & - & 95.78 & 100 \\
\hline
\end{tabular}

as shown in table 3. The Spearman correlation coefficients were $0.321-0.735$.

Inter-rater reliability served as a metric for assessing the reliability of the tool. The inter-rater reliability of the final screening of 338 samples by two screening nurses was measured by calculating the weighted kappa coefficient. The kappa coefficient was 0.89 .

Nutritional risk screenings of the subjects were performed at admission and then weekly until discharge, and the mean (range) frequency of screenings was 1.18 (1-5). The time it took the two screeners to complete each screening was recorded, and the mean (SD) time to completion of screening was 4.22 (1.17) $\mathrm{min}$.

\section{Clinical characteristics of newborns in the three risk groups Comparison of general data}

The general data of the newborns in the three risk groups are listed in table 4 . In the statistical analysis of the birth situation, the differences among all the variables except sex were statistically significant; gestational age and birth weight decreased with increasing nutritional risk level $(\mathrm{p}=0.000, \mathrm{p}=0.000, \mathrm{p}=0.015$ and $\mathrm{p}=0.000)$, while length of hospital stay increased. The differences in length and head circumference at admission, the total serum protein level and the albumin level at admission between the three risk groups were statistically significant and decreased with increasing nutritional risk level $(p=0.000$, $\mathrm{p}=0.000, \mathrm{p}=0.000$ and $\mathrm{p}=0.000)$.

\section{Comparison of growth states}

The comparison of growth states for newborns in different risk groups is shown in table 5. The differences in discharge weight, supine length and head circumference were statistically significant and decreased with increasing risk level $(\mathrm{p}=0.000, \mathrm{p}=0.000$ and $\mathrm{p}=0.000)$. However, there was no significant difference in the growth of physical indicators (weight, head circumference and supine length) among the three risk groups $(\mathrm{p}=0.122, \mathrm{p}=0.400$ and $\mathrm{p}=0.266)$.

\section{Comparison of nutritional intake}

The comparison of nutritional intake for the newborns in the different risk groups is presented in table 6 . According to the 2013 guidelines for the clinical application of neonatal nutrition support in China, the daily caloric intake of premature infants and term infants should reach $110 \mathrm{kcal} / \mathrm{kg}$ and $105 \mathrm{kcal} / \mathrm{kg}$, respectively, and the daily protein intake of premature infants and term infants should reach $3.5 \mathrm{~g} / \mathrm{kg}$ and $2 \mathrm{~g} / \mathrm{kg}$, respectively. ${ }^{18}$ In the comparison of nutritional intake among the three risk groups, there were significant differences in all nutritional intake items except cases that met the calorie standard $(\mathrm{p}=0.007, \mathrm{p}=0.000, \mathrm{p}=0.005$ and $\mathrm{p}=0.000)$. The total intake of calories and protein and the total number of cases that met the standard level of protein intake and parenteral nutritional support were higher in the medium-risk group than in the low-risk group, and the total protein intake and the total number of cases that met the standard level of protein intake were higher in the high-risk group than in the low-risk group. The rate of parenteral nutrition support increased with increasing nutritional risk grade.

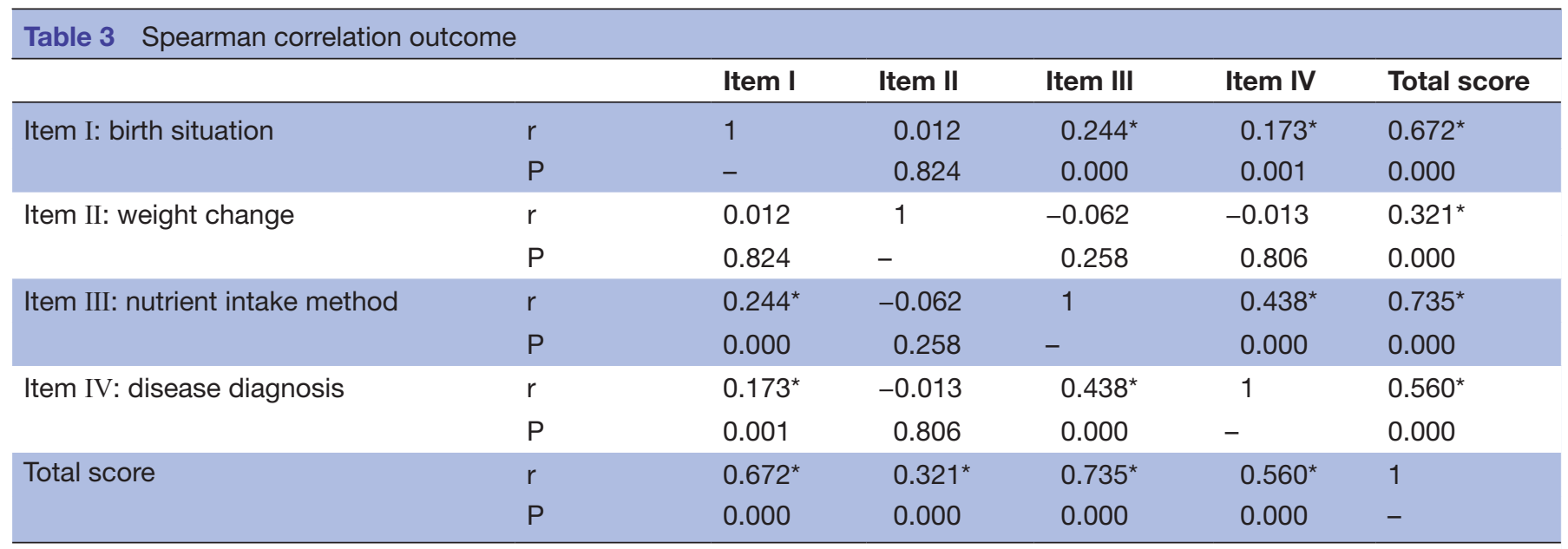

${ }^{*} \mathrm{P}<0.05$. 
Table 4 The general data of the neonates at different risk levels

\begin{tabular}{|c|c|c|c|c|c|}
\hline Characteristic & Low risk & Medium risk & High risk & $\begin{array}{l}\text { Statistical } \\
\text { value }\end{array}$ & $P$ value \\
\hline Male/female (n) & $62 / 44$ & $93 / 73$ & $43 / 23$ & 1.622 & 0.444 \\
\hline Birth weight (mean (SD), g) & 3233.8 (434.9) & $2561.6(643.3)^{\star}$ & $2104.2(624.7)^{\star} \dagger$ & 83.689‡ & $0.000 \ddagger$ \\
\hline Caesarean delivery (n (\%)) & $46(43.4)$ & $93(56.0)$ & $43(65.2)^{\star}$ & 8.369 & 0.015 \\
\hline $\begin{array}{l}\text { Length on admission (median (P25, } \\
\text { P75), cm) }\end{array}$ & $50.0(50.0,51.3)$ & $47.0(45.0,50.0)^{\star}$ & $45.0(42.0,48.0)^{\star} \dagger$ & 97.029 & 0.000 \\
\hline $\begin{array}{l}\text { Head circumference on admission } \\
\text { (median (P25, P75), cm) }\end{array}$ & $34.0(33.0,34.9)$ & $32.0(30.0,33.0)^{*}$ & $30.0(27.4,31.6)^{\star} \dagger$ & 110.102 & 0.000 \\
\hline
\end{tabular}

${ }^{*}$ Compared with the low-risk group, the difference was statistically significant.

†Compared with the medium-risk group, the difference was statistically significant.

fF test (variance analysis).

Comparison of incidences of complications among neonates at different risk levels

The comparison of various complications in neonates at different risk levels during hospitalisation is presented in table 7 . There were statistically significant differences in the prevalence of all diseases except milk protein allergies, gastro-oesophageal reflux and hyperbilirubinaemia among the different risk groups, and the incidence of necrotising enterocolitis and congenital gastrointestinal malformation increased with increasing nutrition risk level.

\section{DISCUSSION}

Nutritional risk screening is an important part of nutrition management, but there is no nutritional risk screening tool for newborns in China. In our previous research, a nutritional risk screening tool for newborns was developed by a group of Chinese experts. This research further demonstrates that the results of the validation of the NNRST are reliable. This tool can be used to preliminarily evaluate the degree of neonatal nutritional risk in China, but its ability to predict clinical outcomes needs to be determined in studies with larger samples.

The data in this study demonstrate the screening accuracy of the NNRST, which can be used to present the clinical characteristics of neonates in different risk level groups. Our research shows that the NNRST has a sensitivity of $85.11 \%$, a specificity of $91.07 \%$, a positive predictive value of $60.61 \%$ and a negative predictive value of $97.43 \%$; all of these values, but particularly the specificity and negative predictive value, are higher than those of other nutritional risk screening tools for newborns. ${ }^{13} 14$ This tool seems able to screen high-risk infants effectively and predictably. In addition, the accuracy of the tool might be higher for low-risk and medium-risk infants than for high-risk infants. Due to the absence of a gold standard

Table 5 Growth states of neonates with different risk levels

\begin{tabular}{|c|c|c|c|c|c|c|}
\hline Groups & $\begin{array}{l}\text { Weight at } \\
\text { discharge } \\
\text { (mean (SD), g) }\end{array}$ & $\begin{array}{l}\text { Weight gain } \\
\text { (mean (SD), } \\
\text { g/day) }\end{array}$ & $\begin{array}{l}\text { Head circumference } \\
\text { at discharge } \\
\text { (median (P25, P75), } \\
\text { cm) }\end{array}$ & $\begin{array}{l}\text { Head } \\
\text { circumference } \\
\text { growth } \\
\text { (median (P25, } \\
\text { P75), cm/weeks) }\end{array}$ & $\begin{array}{l}\text { Length at } \\
\text { discharge } \\
\text { (mean (SD), } \\
\mathrm{cm} \text { ) }\end{array}$ & $\begin{array}{l}\text { Increase in } \\
\text { length } \\
\text { (median (P25, } \\
\text { P75), cm/ } \\
\text { weeks) }\end{array}$ \\
\hline Low risk & $3408.3(481.4)$ & $25.1(27.0)$ & $34.5(33.5,35.2)$ & $0.3(0.0,0.8)$ & $51.6(3.5)$ & $0.5(0.0,0.8)$ \\
\hline Medium risk & $2774.5(601.5)^{\star}$ & $21.5(18.1)$ & $32.5(31.4,34.0)^{\star}$ & $0.4(0.1,0.6)$ & $49.2(4.1)^{\star}$ & $1.0(0.4,1.4)$ \\
\hline$P$ value & $0.000 \ddagger$ & $0.122 \ddagger$ & 0.000 & 0.400 & $0.000 \ddagger$ & 0.266 \\
\hline
\end{tabular}

${ }^{*}$ Compared with the low-risk group, the difference was statistically significant.

†Compared with the medium-risk group, the difference was statistically significant.

$\ddagger \mathrm{F}$ test (variance analysis). 
Table 6 Nutrient intake of neonates at different risk levels

\begin{tabular}{|c|c|c|c|c|c|}
\hline Groups & $\begin{array}{l}\text { Caloric intake } \\
\text { (mean (SD), } \\
\text { kcal/(kg·day)) }\end{array}$ & $\begin{array}{l}\text { Protein intake } \\
\text { (mean (SD), g/ } \\
(\mathrm{kg} \cdot \text { day)) }\end{array}$ & $\begin{array}{l}\text { Cases that } \\
\text { met the caloric } \\
\text { standard } \\
(\mathrm{n}(\%))\end{array}$ & $\begin{array}{l}\text { Cases that met } \\
\text { the protein } \\
\text { standard (n (\%)) }\end{array}$ & $\begin{array}{l}\text { Parenteral } \\
\text { nutritional } \\
\text { support } \\
\text { (n (\%)) }\end{array}$ \\
\hline Low risk & 82.7 (23.9) & $1.7(0.6)$ & 19 (17.9) & 20 (18.9) & $21(19.8)$ \\
\hline Medium risk & $91.5(21.9)^{\star}$ & $2.6(0.7)^{\star}$ & $31(18.7)$ & $62(37.3)^{\star}$ & $117(70.5)^{\star}$ \\
\hline High risk & 86.8 (21.2) & $2.8(0.7)^{\star}$ & $6(9.1)$ & $19(28.8)^{*}$ & $63(95.5)^{*} \dagger$ \\
\hline$P$ value & $0.007 \ddagger$ & $0.000 \ddagger$ & 0.188 & 0.005 & 0.000 \\
\hline
\end{tabular}

${ }^{*}$ Compared with the low-risk group, the difference was statistically significant.

†Compared with the medium-risk group, the difference was statistically significant.

$\ddagger \mathrm{F}$ test (variance analysis).

for the validation of nutritional screening tools, ${ }^{19}$ this research adopted anthropometric measurements (incidence of faltering growth) as the reference standard to validate this tool. ${ }^{14}$ In our study, the Chinese neonatal birth weight curve was used to determine whether infants had faltering growth. Because this curve contains updated neonatal birth weight data for different gestational ages in China and shows differences according to sex, it accurately reflects the actual neonatal birth weight. ${ }^{17}$ Furthermore, a systematic review reported that because the use of anthropometric measurements as the reference standard for the validation of malnutrition screening tools tends to produce many false-positive results, full dietetic/ nutritional assessment should be used to identify positive cases. ${ }^{20}$ However, dietetic/nutritional assessments vary across different countries due to differences in educational standards. ${ }^{21}$ Compared with paediatric nutritional risk screening tools that use the full nutritional assessment as the reference standard (eg, the Screening Tool for the Assessment of Malnutrition in Paediatrics and the Paediatric Yorkhill Malnutrition Score had sensitivities of $70 \%$ and $59 \%$, specificities of $91 \%$ and $92 \%$, positive predictive value of $54.8 \%$ and $47 \%$ and a negative predictive value of $94.9 \%$ and $95 \%$, respectively), the NNRST still shows good accuracy. ${ }^{22} 23$

The ESPEN Nutrition Screening Guidelines noted that a qualified screening tool required good predictive value and a high level of reliability and validity. ${ }^{8}$ In this study, the criterion validity explained the correlation between the results of the tool evaluation and the reference standard, which could be shown by the Spearman correlation coefficient $(r)$. The $r$ value was 0.530 , which indicated a significant correlation. This means that the NNRST had a positive effect on predicting and detecting infants with unfavourable clinical outcomes. The scores that infants with faltering growth received were approximately twice as high as those without faltering growth, indicating that the tool could classify the infants' nutritional states effectively. The $r$ values of the four items that could represent the results of the content validity were $0.672,0.321,0.735$ and 0.560 , respectively. These results suggested that the content validity was positively correlated between the total score and each item. Therefore, the contents of the tool were closely related and reasonable. In this study,

Table 7 Incidences of complications among neonates with different risk levels (n (\%))

\begin{tabular}{|c|c|c|c|c|c|}
\hline Complications & Low risk & Medium risk & High risk & $\begin{array}{l}\text { Statistical } \\
\text { value }\end{array}$ & $P$ value \\
\hline $\begin{array}{l}\text { Necrotising enterocolitis/congenital gastrointestinal } \\
\text { malformation }\end{array}$ & $3(2.8)$ & $12(7.2)$ & $27(40.9)^{*} \dagger$ & 62.295 & 0.000 \\
\hline Diarrhoea/alimentary tract haemorrhage & $3(2.8)$ & $16(9.6)$ & $13(19.7)^{\star}$ & 13.512 & 0.001 \\
\hline Milk protein allergy/gastrointestinal reflux & $5(4.7)$ & $12(7.2)$ & $4(6.1)$ & 0.704 & 0.703 \\
\hline Pneumonia & $77(72.6)$ & $157(94.6)^{\star}$ & $57(86.4) \dagger$ & 26.009 & 0.000 \\
\hline Congenital heart disease & $46(43.4)$ & $121(72.9)^{\star}$ & $51(77.3)^{*}$ & 30.424 & 0.000 \\
\hline Brain injury/intracranial haemorrhage & $72(67.9)$ & $145(87.3)^{\star}$ & $60(90.9)^{*}$ & 20.952 & 0.000 \\
\hline Hyperbilirubinaemia & $82(77.4)$ & $108(65.1)$ & $42(63.6)$ & 5.499 & 0.064 \\
\hline Other complications & $29(27.4)$ & $85(51.2)^{\star}$ & $45(68.1)^{\star}$ & 29.479 & 0.000 \\
\hline
\end{tabular}

${ }^{*}$ Compared with the low-risk group, the difference was statistically significant.

†Compared with the medium-risk group, the difference was statistically significant. 
the inter-rater reliability (kappa coefficient) was 0.89 , indicating the stability and consistency of our screening tool. Moreover, the average time to the completion of screening was no more than $5 \mathrm{~min}$ in the study; other studies of paediatric nutritional risk screening tools have reported that the longest time to complete the screening was 48 hours, while the shortest time was $5 \mathrm{~min} .{ }^{24}$ Our findings suggest this screening tool can easily screen out infants with nutritional risk, which satisfies the requirements of a screening tool.

In our study, the NNRST was stratified into three levels, and the differences among the three nutritional risk groups were obvious in all of the comparative analyses. In the comparison of the general data of the neonates, there were significant differences in the birth and admission statuses of the three risk groups. The infants in the high-risk group had a lower gestational age and smaller physical measurements, lower albumin on admission, a longer hospital stay and higher rates of caesarean section than the infants in the moderate-risk and low-risk groups did. However, we did not find a significant correlation between the risk categories assigned by the tool and physical growth during hospitalisation. This result was expected because the median length of hospital stay in our population was only 9 days, and therefore, there were no significant differences in the increase of physical indicators. Furthermore, the comparison of protein intake and cases that met the protein standard shows that there were more infants with high and medium risk than infants with low risk. It is possible that the infants in the high-risk or medium-risk group were more premature, had more severe illness and had a high demand for proteins and that therefore, during the treatment process, doctors were more sensitive to their needs for parenteral nutritional supplementation. In contrast, the infants in the low-risk group may have had a generally good condition compared with those in the high-risk and medium-risk groups, which led to the assumption that they did not and would not require parenteral nutrition supplement, and their protein source was limited to formula; however, the influence of the disease and environmental factors can result in reduced milk intake, which can lead to a lessthan-ideal protein intake and success rate. The comparison of the complication incidence among the neonates at three risk levels showed that the incidences of necrotising enterocolitis and congenital malformations of the digestive tract were significantly different among the three risk groups; the incidence of diseases during hospitalisation were highest in the high-risk group, making their situations more serious and complicated.

The results of our validation of this tool suggest that it can be used in practice by professionally trained nurses to screen for nutritional risk in hospitalised neonates. Infants whose screening results indicate high risk should be reported to the nutrition team so that interventions can be developed early. However, it is still necessary to routinely monitor growth indicators and dynamically screen for nutritional risk in infants with medium risk.
At present, neonatal nutritional management in China is insufficient, and this tool may provide some reference for neonatal nutritional risk screening.

\section{Limitations of this study}

Our study had some limitations. First, the neonatal weight gain curve published in 2015 was meant for infants with gestational ages ranging from 24 to 42 weeks. Due to limitations in the scope of this study, we could not determine whether the growth of post-term infants revealed malnutrition. Therefore, this study did not include post-term infants. Second, the ward had very strict clinical management requirements for premature infants less than 30 weeks of gestational age, and the number of premature infants admitted at that time was very low; therefore, this study did not include newborns $<30$ weeks of gestational age, which may have led to bias in our study. Finally, the risk categories were determined according to the scoring principle and the weight of the AHP, and future studies are needed to determine whether classification into highrisk and low-risk categories with this tool makes screening more convenient for medical staff.

\section{CONCLUSIONS}

This study verifies the accuracy, validity and reliability of the NNRST. The tool is a scale that provides an economical, handy and non-invasive method for screening neonates for nutritional risk. By combining several assessment indicators, this tool, which satisfies the conditions and requirements for nutritional risk tools, provides a dynamic method for regular preliminary screening for nutritional risk among hospitalised neonates in China.

\section{Author affiliations}

${ }^{1}$ Department of Neonatology, Children's Hospital of Chongqing Medical University, Ministry of Education Key Laboratory of Child Development and Disorders, National Clinical Research Center for Child Health and Disorders, Chongqing Key Laboratory of Paediatrics, China International Science and Technology Cooperation Base of Child Development and Critical Disorders, Chongqing, China

${ }^{2}$ Department of Primary Healthcare, Children's Hospital of Chongqing Medical University, Ministry of Education Key Laboratory of Child Development and Disorders, National Clinical Research Center for Child Health and Disorders, Chongqing Key Laboratory of Paediatrics, China International Science and Technology Cooperation Base of Child Development and Critical Disorders, Chongqing, China

Acknowledgements The authors gratefully acknowledge Yuan Shi and Jianhui Wang, who provided assistance with the submission and revision of the manuscript.

Contributors All five authors made substantial contributions to the study and manuscript and met the criteria for authorship that are defined in the author instructions. MZ and YL contributed to the acquisition, analysis and interpretation of the data and the drafting of the manuscript. $\mathrm{HY}, \mathrm{XZ}$ and $\mathrm{YH}$ contributed to the design and conduct of the study. HY supervised the project and provided critical revision and final approval of the manuscript. The corresponding author attests that all listed authors meet the authorship criteria and that no one who met the criteria has been omitted.

Funding This study was supported by grants from the Shapingba District of Chongqing Decision-making Consultation and Management Innovation Mandatory Plan Project (jc201513) and the Clinical Research Project of Children's Hospital of Chongqing Medical University (Icyj2015-14).

Competing interests None declared. 
Patient and public involvement Patients and/or the public were not involved in the design, or conduct, or reporting, or dissemination plans of this research.

Patient consent for publication Not required.

Ethics approval This study was approved by the Medical Ethics Review Committee of Children's Hospital of Chongqing Medical University, China (approved no. 61/2015).

Provenance and peer review Not commissioned; externally peer reviewed.

Data availability statement Data are available on reasonable request.

Open access This is an open access article distributed in accordance with the Creative Commons Attribution Non Commercial (CC BY-NC 4.0) license, which permits others to distribute, remix, adapt, build upon this work non-commercially, and license their derivative works on different terms, provided the original work is properly cited, appropriate credit is given, any changes made indicated, and the use is non-commercial. See: http://creativecommons.org/licenses/by-nc/4.0/.

ORCID iD

Huaying Yin http://orcid.org/0000-0003-3054-8563

\section{REFERENCES}

1 Kozuki N, Lee ACC, Black RE, et al. Nutritional and reproductive risk factors for small for gestational age and preterm births. Nestle Nutr Inst Workshop Ser 2015;81:17-28.

2 Johnson MJ, Wiskin AE, Pearson F, et al. How to use: nutritional assessment in neonates. Arch Dis Child Educ Pract Ed 2015;100:147-54.

3 Zalewski BM, Patro B, Veldhorst M, et al. Nutrition of infants and young children (one to three years) and its effect on later health: a systematic review of current recommendations (EarlyNutrition project). Crit Rev Food Sci Nutr 2017;57:489-500.

4 Wiedmeier JE, Joss-Moore LA, Lane RH, et al. Early postnatal nutrition and programming of the preterm neonate. Nutr Rev 2011;69:76-82.

5 Rice MS, Valentine CJ. Neonatal body composition: measuring lean mass as a tool to guide nutrition management in the neonate. Nutr Clin Pract 2015;30:625-32.

6 Pierro A, Eaton S. Metabolism and nutrition in the surgical neonate. Semin Pediatr Surg 2008;17:276-84.

7 Altman M, Edstedt Bonamy A-K, Wikström A-K, et al. Cause-Specific infant mortality in a population-based Swedish study of term and post-term births: the contribution of gestational age and birth weight. BMJ Open 2012;2:e001152. doi:10.1136/bmjopen-2012-001152

8 Kondrup J, Allison SP, Elia M, et al. ESPEN guidelines for nutrition screening 2002. Clin Nutr 2003;22:415-21.
9 Elia M, Stratton RJ. An analytic appraisal of nutrition screening tools supported by original data with particular reference to age. Nutrition 2012;28:477-94.

10 van Bokhorst-de van der Schueren MAE, Guaitoli PR, Jansma EP, et al. Nutrition screening tools: does one size fit all? A systematic review of screening tools for the hospital setting. Clin Nutr 2014;33:39-58.

11 Randall Simpson J, Gumbley J, Whyte K, et al. Development, reliability, and validity testing of toddler NutriSTEP: a nutrition risk screening questionnaire for children 18-35 months of age. Appl Physiol Nutr Metab 2015;40:877-86.

12 Zhang $\mathrm{H}$, Wang $\mathrm{Y}$, Jiang Z-M, et al. Impact of nutrition support on clinical outcome and cost-effectiveness analysis in patients at nutritional risk: a prospective cohort study with propensity score matching. Nutrition 2017;37:53-9.

13 Groh-Wargo S. Nutritional care for high-risk newborns. Rev.3rd. Chicago, IL: Precept Press, 2000.

14 Johnson MJ, Pearson F, Emm A, et al. Developing a new screening tool for nutritional risk in neonatal intensive care. Acta Paediatr 2015;104:e90-3.

15 Yuwei L, Huaying Y, Xianhong Z. To be clinical validated for a nutritional risk screening tool of neonates. CJCN 2017;25:111-7.

16 Zhu L, Zhang R, Zhang S, et al. [Chinese neonatal birth weight curve for different gestational age]. Zhonghua Er Ke Za Zhi 2015;53:97-103.

17 Zhiguang M, Shaoxia L, Aizhen L. A study on the diagnosis of neonatal malnutrition and Fellow-up of the infants. CJCHC 2002.

18 Chinese Society for Parenteral and Enteral Nutrition. Guidelines for the clinical application of neonatal nutrition support in China. J Clin Pediatr 2013;31:1177-82.

19 Wonoputri N, Djais JTB, Rosalina I. Validity of nutritional screening tools for hospitalized children. J Nutr Metab 2014;2014:1-6.

20 Klanjsek P, Pajnkihar M, Marcun Varda N, et al. Screening and assessment tools for early detection of malnutrition in hospitalised children: a systematic review of validation studies. BMJ Open 2019;9:e025444.

21 Joosten KFM, Hulst JM. Prevalence of malnutrition in pediatric hospital patients. Curr Opin Pediatr 2008;20:590-6.

22 Gerasimidis K, Keane O, Macleod I, et al. A four-stage evaluation of the paediatric Yorkhill malnutrition score in a tertiary paediatric hospital and a district general Hospital. Br J Nutr 2010;104:751-6.

23 McCarthy H, Dixon M, Crabtree I, et al. The development and evaluation of the screening tool for the assessment of malnutrition in paediatrics (STAMPC) for use by healthcare staff. J Hum Nutr Diet 2012;25:311-8.

24 Joosten KFM, Hulst JM. Nutritional screening tools for hospitalized children: methodological considerations. Clin Nutr 2014;33:1-5.

25 Mehta S, Tandon A, Dua T, et al. Clinical assessment of nutritional status at birth. Indian Pediatr 1998;35:423-8. 